\title{
More Antiretroviral Drugs Will Reduce Stigma and Discrimination in West Africa Lionel Morgan*‡
}

\author{
Address: HILLS, Monrovia, Liberia \\ Email: Lionel Morgan* - flionelmorgan@yahoo.com \\ * Corresponding author ‡Presenting author
}

\author{
from 2005 International Meeting of The Institute of Human Virology \\ Baltimore, USA, 29 August - 2 September 2005 \\ Published: 8 December 2005 \\ Retrovirology 2005, 2(SuppI I):PI33 doi:I0.I I86/I742-4690-2-SI-PI33
}

\section{Background}

In West Africa, the high level of Stigma and discrimination attached to the victims of HIV/AIDS is due to the lack of many factors including the lack of free and cheaper antiretroviral drugs. This is due to poverty on the part of victims and the lack of good policies by the government to subsidise ARVs.

\section{Methods}

Discussing sexuality issues publicly in West Africa is like a taboo, therefore several techniques have to be adopted inorder to collect adequate informationfor analysis.

The information collected was drawn from four countries, namely; Liberia, Ivory Coast, Ghana and Benin. In the process, schools refugee camps internally displaced campsnight clubs bars and other public places including market grounds and youth centers. Interviews were conducted and questionaires were given at times and also group discussionswere held inorder to get the individual and general view of the masses.

\section{Results}

The assessment passed out well with just few minor obstacles relating to some discussions in some areas forbidden by social customs and traditions. In total 300 persons were surveyed, ages 12 to 25 . Ninety percent of illiterate the people know that AIDS is a sickness but do not know how it is transmitted, whereas $50 \%$ of the students know that AIDS exist and it is real but do not know the actual root causes or what even the acronym stands for. About $20 \%$ of them do not know the difference between high risk behavior and low risk ones. About $98 \%$ of the students agree that stigma and discrimination affects the rate

of growth of infected persons whilst $40 \%$ of sexually active youthsaid that they do not like the use of condoms. About $85 \%$ of them said that they can never befriend someone with AIDS i.e they cannot eat, talk, shakehandsor share clothes. Surprisingly $23 \%$ said that if the doctor tells them that they are HIV positive they will either commit suicide or get extraordinarily promiscuous to spread the disease and not to die alone.

\section{Conclusion}

It is possible to decrease stigma and discrimination by providing information on HIV/AIDS. This should focus on what the virus is how it can be transmitted and prevented. There should be intensive education on how victims of the pandemic should be treated and cared for.

Governments shoul subsidise the importation of cheaper and safer antiretroviral drugs and and do everything possible to reduce stigma and discrimination as relate to HIV/ AIDS. Stigma and discrimination will be reduced because some hope, at least is provided for a longer and healthier life. If drugs are provided to buttress the counseling received, people will feel comfortable when affected. 